\title{
Mechanisms of Pain in Osteoarthritis
}

\author{
Bruce Kidd, MD
}

Received: 31 August 2011/Accepted: 6 December 2011/Published online: 23 February 2012

(C) The Author(s) 2012. This article is published with open access at Springerlink.com

Keywords osteoarthritis ·pain - inflammatory mediators . peripheral sensitization $\cdot$ central sensitization

\section{Introduction}

In the past, pain mechanisms in osteoarthritis (OA) have received surprisingly little attention, although this is now changing. Attempts to discriminate between $\mathrm{OA}$ and other rheumatologic disorders, such as rheumatoid arthritis, through verbal descriptions of pain have generally proved unsuccessful as the patterns of pain often overlap. Userelated pain in $\mathrm{OA}$ is common but rest pain and night pain sometimes occur, and a variety of patterns of pain are described by different patients, varying from a dull ache to sharp, stabbing pains [1]. It seems probable that a variety of different mechanisms contribute to symptoms in this disorder and that the relative importance varies among individuals.

The presence and severity of joint pain correlate poorly with structural evidence of joint damage. Current evidence suggests that OA joint damage predisposes to pain, but that little correlation between pain severity and the extent of joint damage exists. The probable explanation of these observations lies in that fact that pain perception arises in response to a complex series of underlying neurophysiologic events involving transduction of stimuli, transmission of encoded information, and subsequent modulation of this activity at both peripheral and more central levels. In all but acute situations, the relation between tissue injury and resultant symptoms becomes less well defined and more susceptible to extraneous influences originating both within and external to the individual.

Minor injuries or damage within the joint produce short lived excitation of specialized high threshold nociceptors with brief, spatially localized pain. More severe tissue damage associated with the release of inflammatory mediators produces not only direct nociceptor excitation,

B. Kidd MD $(\bowtie)$

Barts and The London School of Medicine, Queen Mary University of London, London, England, UK e-mail: b.l.kidd@qmul.ac.uk but also modified response properties to subsequent stimuli (peripheral sensitization) [2]. Under these circumstances, the response to a noxious stimulus becomes exaggerated. Alternatively, normally innocuous stimuli such as standing or walking may produce pain.

\section{Pathophysiology of Joint Pain}

Mammalian synovial joints are richly supplied with sensory nerve fibers, the terminals of which express multiple receptors that characteristically become active across relatively narrow ranges of stimulus intensity. The sensitivity of these receptors is governed by a critical interaction with the local microenvironment as well as by factors related to previous stimuli. The cellular mechanisms by which these changes occur involve early post-translational changes to receptor ion channels and later, longer lasting transcriptiondependent mechanisms involving changes to the chemical phenotype of the cell [3] (Fig. 1).

Parallel changes to those observed in the periphery occur at more central levels (central sensitization) (Fig. 2). At a spinal level, this involves exaggerated responses to normal stimuli together with expansion of receptive field size producing tenderness and referred pain in areas away from the site of injury [4]. Functional imaging studies of the brain following noxious stimuli using fMRI and PET show a complex pattern with discrete areas of activity throughout both cerebral hemispheres [5]. The consequences of cortical sensitization remain unclear, but may produce the state of hypervigilance and other more general phenomenon observed in patients with chronic pain.

\section{Mediators of Pain in OA}

Several lines of evidence point to the importance of mediators released from either synovium or bone as being important to symptoms in OA. The presence of knee pain has been shown to correlate with MRI findings of moderate or larger effusions as well as synovial thickening [6]. Bone marrow lesions detected on MRI are more prevalent in 


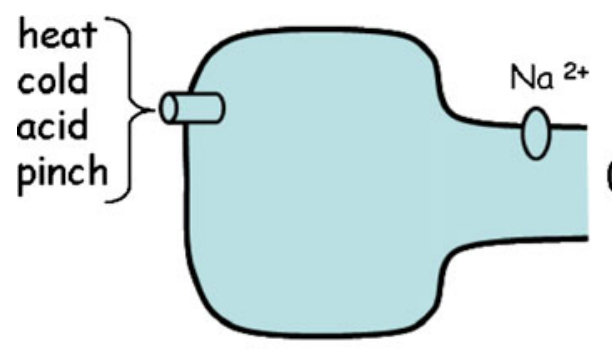

(A) Acute

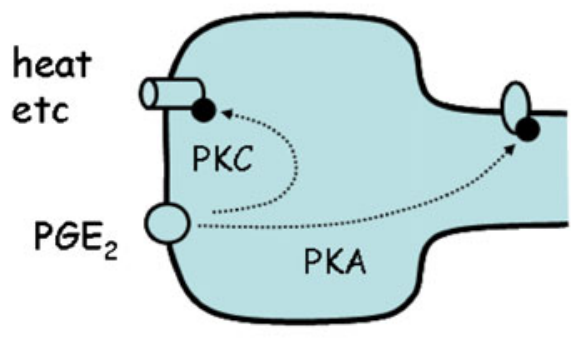

(B) Peripheral sensitization (early)

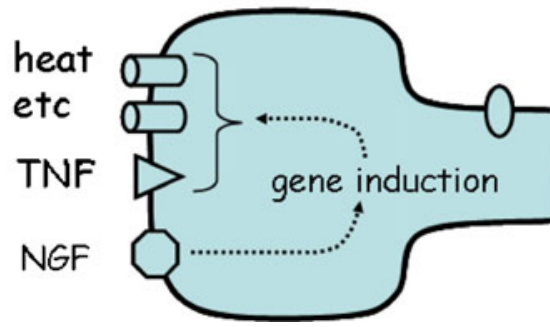

(C) Peripheral sensitization (late)

Fig. 1. Peripheral sensitization. Contribution of peripheral nociceptors to pain. a Acute pain: Noxious stimuli activate high threshold ion channels with resultant propagation of axon potentials. b Early phase sensitization: Mediators, including prostaglandin E2, activate kinases to phosphorylate receptors/ion channels and lower threshold for activation. c Late phase sensitization: Gene induction in response to growth factors resulting in changes to cell phenotype. Adapted from [16]. Adapted with permission of John Wiley \& Sons, Inc.

individuals with OA who have knee pain than in those who are symptom-free [4]. Changes in bone marrow lesions and synovitis are associated with fluctuations in knee pain in patients with knee $\mathrm{OA}$, and pain resolution occurs more frequently when bone marrow lesions become smaller [14].

Potential peripheral targets to control OA pain currently under investigation include inflammatory mediators and their key receptors such as prostanoids, kinins, cytokines, and chemokines; sodium and calcium ion channels; and growth factors [9]. An example of the latter is nerve growth factor (NGF), which is produced by various cell types including fibroblasts, keratinocytes, Schwann cells, and a range of immune cells. Acting via neuronal trkA receptors, NGF sensitizes articular pain fibers and changes pain thresholds [10]. Blocking activity of NGF with a neutralizing humanized monoclonal antibody (tanezumab) has been shown to reduce OA knee pain [11]. However, accelerated joint damage with radiographic evidence of bone necrosis resulting in knee replacement has been reported in some patients, resulting in the FDA putting clinical trials with this compound on hold. Reasons for the

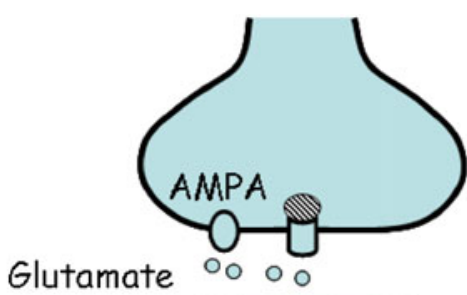

(A) Acute
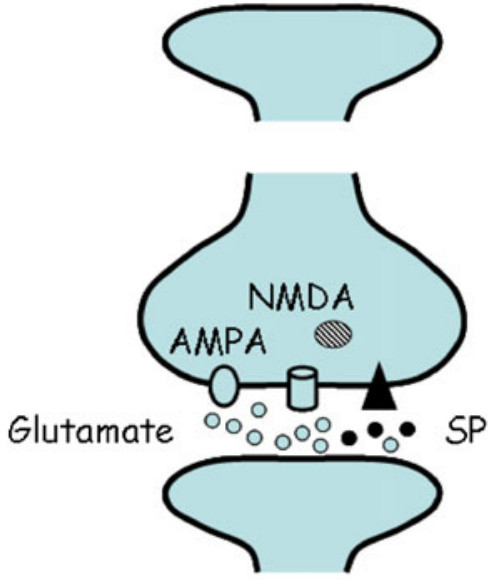

(B) Central sensitization (early)

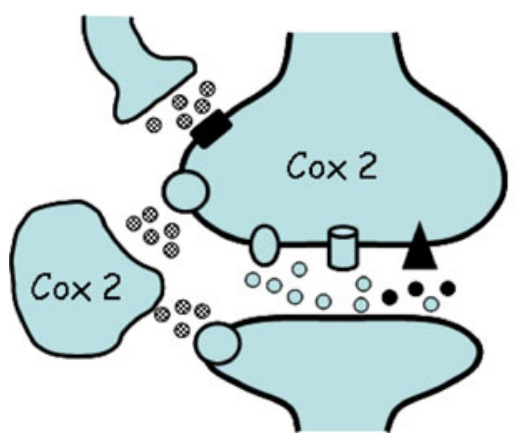

(C) Central sensitization (late)

Fig. 2. Central sensitization. Contribution of spinal cord neurones to pain. a Acute pain: Activation of AMPA receptor by glutamate. NMDA receptor blocked. b Early phase sensitization: Activation of NMDA receptor following removal of magnesium ion block [mediated by substance $\mathrm{P}(S P)$ acting on NK1 receptors-black spheres and triangle, respectively]. c Late phase sensitization: Gene induction with enhanced production of prostaglandins and other local mediators. Modulation by descending facilitatory/inhibitory pathways. Adapted from [16]. Adapted with permission of John Wiley \& Sons, Inc.

accelerated damage remain unclear, but the episode raises enormously important issues for the development of future analgesics for OA. One explanation given has been that the absence of joint pain led to excessive wear; however, other possibilities include a cross-reaction between tanzemab and other (vascular) receptors or an as yet unidentified trophic role for NGF in maintenance of joint homeostasis.

Psychophysical studies of patients with symptomatic OA have reported diffuse alteration of pain perception in response to various stimuli [12] with subjects having increased pain intensity and significantly larger referred and radiating pain areas than matched controls. Local changes to nociceptive activity are highly unlikely to account for these findings and point to the presence of enhanced central pain processing in OA. Consistent with this, studies that have combined psychophysical methods with functional brain imaging have 
reported increased activation in the brainstem of OA patients following punctuate stimulation compared to controls [13]. OA pain has also shown to be associated with increased activity in areas concerned with the processing of fear and emotions and in averse conditioning, including the cingulate cortex, the thalamus, and the amygdala [14]. This is in accord with other studies showing an important relationship between psychosocial factors and pain reporting in OA, particularly anxiety, depression, catastrophizing, coping strategies, and social isolation [15].

\section{Conclusions}

It seems likely that OA pain reflects a state of altered pain processing such that everyday stimuli are perceived as being painful. These changes arise in response to a critical interaction with particular joint, bone, and periarticular factors that may well vary among individuals. The resultant sensitization of nociceptive pathways at both peripheral and central levels is then dependent on constitutional factors unique to an individual — such as gender, age, and previous history, as well as environmental factors including culture and lifestyle.

Disclosures Each author certifies that he or she has no commercial associations (e.g., consultancies, stock ownership, equity interest, patent/licensing arrangements, etc.) that might pose a conflict of interest in connection with the submitted article.

Open Access This article is distributed under the terms of the Creative Commons Attribution Noncommercial License which permits any noncommercial use, distribution, and reproduction in any medium, provided the original author(s) and source are credited.

\section{References}

1. Hawker GA, Stewart L, French MR, Cibere J, Jordan JM, March L, Suarez-Almazor M, Gooberman-Hill R. Understanding the pain experience in hip and knee osteoarthritis - an OARSI/OMERACT initiative. Osteoarthritis Cartilage. 2008 Apr;16(4):415-22.

2. Raja S, Meyer R, Kingkamp M, JN C. Peripheral neural mechanisms of nociception. In: Wall P, Melzac R, editors.
Textbook of pain. Edinburgh: Churchill Livingstone; 1999. p. $11-58$.

3. Woolf C, J, Costigan M. Transcriptional and posttranslational plasticity and the generation of inflammatory pain. Proc Natl Acad Sci 1999;96:7723-7730.

4. Coderre T, Katz J, Vaccarino A, Melzack R. Contribution of central neuroplasticity to pathological pain: review of clinical and experimental evidence. Pain 1993;52:259-285.

5. Gracely RH, Petzke F, Wolf JM, Clauw DJ. Functional magnetic imaging evidence of augmented pain processing in fibromyalgia. Arthritis Rheum 2002; 46; 1333-1343.

6. Hill CL, Gale DG, Chaisson CE, Skinner K, Kazis L, Gale ME, Felson DT. Knee effusions, popliteal cysts, and synovial thickening: association with knee pain in osteoarthritis. J Rheumatol. 2001 Jun;28(6):1330-7.

7. Felson DT, Chaisson CE, Hill CL, Totterman SM, Gale ME, Skinner KM, Kazis L, Gale DR. The association of bone marrow lesions with pain in knee osteoarthritis. Ann Intern Med. $2001 \mathrm{Apr}$ 3;134(7):541-9

8. Zhang Y, Nevitt M, Niu J, Lewis C, Torner J, Guermazi A, Roemer F, McCulloch C, Felson DT. Fluctuation of knee pain and changes in bone marrow lesions, effusions, and synovitis on magnetic resonance imaging. Arthritis Rheum. 2011 Mar;63(3):691-9. doi: 10.1002/art.30148.

9. Dray A, Read SJ. Arthritis and pain. Future targets to control osteoarthritis pain. Arthritis Res Ther. 2007;9(3):212.

10. Wood JN. Nerve growth factor and pain. N Engl J Med. 2010 Oct 14;363(16):1572-3

11. Lane NE, Schnitzer TJ, Birbara CA, Mokhtarani M, Shelton DL, Smith MD, Brown MT. Tanezumab for the treatment of pain from osteoarthritis of the knee. N Engl J Med. 2010 Oct 14;363 (16): 1521-31

12. Bajaj P, Bajaj P, Graven-Nielsen T, Arendt-Nielsen L: Osteoarthritis and its association with muscle hyperalgesia: An experimental contolled study. Pain 93:107, 2001.

13. Gwilym SE, Keltner JR, Warnaby CE, Carr AJ, Chizh B, Chessell I, Tracey I. Psychophysical and functional imaging evidence supporting the presence of central sensitization in a cohort of osteoarthritis patients. Arthritis Rheum. 2009 Sep 15;61(9):122634.

14. Kulkarni B, Bentley DE, Elliott R, Julyan PJ, Boger E, Watson A, Boyle Y, El-Deredy W, Jones AK. Arthritic pain is processed in brain areas concerned with emotions and fear. Arthritis Rheum. 2007 Apr;56(4):1345-54.

15. Sullivan M, Tanzer M, Stanish W, Fallaha M, Keefe FJ, Simmonds M, Dunbar M. Psychological determinants of problematic outcomes following Total Knee Arthroplasty. Pain. 2009 May; 143(1-2):123-9

16. Kidd BL, McDougall JJ, Inglis JJ (2009) Inflammatory mediators in nociception. In: Felson DT, Schaible H-G (eds) Pain in osteoarthritis. Wiley, New York, pp 55-72. 